Chapter 5

\title{
Clinical, Laboratory and Ultrasonographic Evaluation of Patients with Acute Schistosomiasis Mansoni
}

\author{
Matheus Fernandes Costa-Silva**, \\ Denise da Silveira-Lemos**, \\ Amanda Cardoso de Oliveira Silveira, \\ Pedro Henrique Gazzinelli-Guimarães, \\ Helena Barbosa Ferraz, Cristiano Lara Massara, \\ Martin Johannes Enk, \\ Maria Carolina Barbosa Álvares, \\ Olindo Assis Martins-Filho, \\ Paulo Marcos Zech Coelho, Rodrigo Corrêa-Oliveira, \\ Giovanni Gazzinelli and Andréa Teixeira-Carvalho \\ Additional information is available at the end of the chapter
}

http://dx.doi.org/10.5772/53047

\section{Introduction}

Schistosomiasis is a parasite chronic disease caused by the helminth of genus Schistosoma. The infection is common in parts of Africa, South America, Middle East, Caribbean and Asia where it is a leading cause of morbidity and mortality [1]. Recent estimates suggest there are 700 million people at risk worldwide with almost 200 million infected in Africa alone [2]. In Brazil, the schistosomiasis infection is caused by Schistosoma mansoni, where estimates suggest a range from 2.5 million [3, 4] to 12 million people infected [5]. In the state of Minas Gerais, schistosomiasis mansoni is prevalent in 519 out of 853 municipalities, with an estimated number of one million infected people in an area of $300.000 \mathrm{~km}^{2}$ [6].

One of the greatest public health problems in countries where the disease is highly endemic, including Brazil, is schistosomiasis control for the following reasons: (a) large intermediary hosts dissemination and their escape mechanisms from molluscicides and from biological 
control due to high costs and low efficacy; (b) high charges associated with implementation of sanitary conditions and water supply and the intense contact of rural population with polluted water, as well as engagement in agricultural and fishing activities; (c) the long time needed for sanitary education and for the community to adhere to controlling programs; (d) individual or massive treatment has been shown efficient for controlling the morbidity, but not for reducing prevalence due to reinfection; (e) individual protection is unlikely, except for specific groups of exposed people; (f) until the current days, there is no effective vaccine for preventing schistosomiasis $[7,8]$.

According to previous data published by our group [9, 10], the proliferation of rural tourism in endemic areas may be an important contributing factor to the outbreak of schistosomiasis cases. The preservation of natural environment on the site, in order to attract visitors from urban centers, unintentionally contributes to create an ideal habitat for the intermediate host. Additionally, most areas chosen for leisure activities accommodate rural communities without any type of sanitation and, thus, represent a permanent risk of contamination of the flowing water.

In this context, visitors from urban areas, who never had previous contact with the parasite, contract the infection, and develop acute schistosomiasis [11]. Acute schistosomiasis is associated with a primary exposure and is more commonly seen in non-immune individuals traveling through endemic regions [12]. The clinical symptoms most commonly observed in such patients include fever, general weakness, headache, nausea, vomiting, diarrhea, anorexia, colic, weight loss, dry cough and hepatosplenomegaly accompanied by marked eosinophilia and leucocytosis [13-16]. However, these clinical symptoms may be confused with a number of infections such as visceral leishmaniasis, typhoid fever, malaria, tuberculosis, viral hepatitis, mononucleosis and bacterial infections [17]. Hence, the diagnosis of acute schistosomiasis becomes a challenge for the assistant doctor due to the wide diversity of non-specific symptoms presented by the patients; in addition, the presence of eggs in stool may not to be easily detected by parasitological examination in this phase of the infection.

Abdominal ultrasound is a complementary tool often used to assist the diagnoses of the S. mansoni infection, mainly on the study of the liver damage caused by the chronic infection. It is an inexpensive method, not radioactive or invasive, which provides immediate results and can be used for epidemiological fieldwork in endemic areas. The hepatic ultrasound pattern in patients with severe hepatosplenic schistosomiasis is characterized by pronounced periportal thickening. However, reports of ultrasound studies in patients with acute schistosomiasis are still scarce [18], and additional trials are necessary to evaluate the benefits and limitations of the ultrasound as a tool of clinical evaluation at the acute phase of the S. mansoni infection [19].

From the immunological point of view, the acute phase of the infection is characterized by a series of humoral and cellular immunological events. Hiatt et al. [20] showed elevations of $\operatorname{IgG}, \operatorname{IgM}$, IgE, and high titers of total antibodies in serum of acute patients that indicated the illness is associated with intense immune activity, while the magnitude of the IgE responses was related to the intensity of the infection. De Jesus et al. [16] showed that there was no significant difference in total IgE level between patients with 
acute and chronic schistosomiasis. In addition, Caldas et al [21] showed that specific IgG, $\operatorname{IgM}$ and IgE titers against egg and worm antigens in acute patients do not differ from those presented by chronic patients. Regarding cellular immunological events, nitric oxide (NO) represents an important and versatile messenger in biological systems, and it has been identified as a cytotoxic factor in the immune system, presenting anti- or proinflammatory properties under different circumstances [22]. Oliveira et al. [23] demonstrated that human peripheral blood mononuclear cells (PBMC) are capable of in vitro $\mathrm{NO}$ production and the inhibition of its production through the addition of $\mathrm{N}$ omega-nitro-L-arginine methyl ester (L-NAME) is responsible for an exacerbated granulomatous reaction.

In this report, we evaluated the clinical/laboratorial parameters and ultrasonographic features of patients who suffered acute schistosomiasis resulting from a simultaneous exposure in a country house in the metropolitan area of Belo Horizonte, Minas Gerais State, Brazil.

\section{Population, materials and methods}

\subsection{Study population}

The patients evaluated in this study acquired the acute phase of S. mansoni infection in a country house in the rural district of the municipality of Igarapé in the metropolitan area of Belo Horizonte, Brazil. The country house is frequently leased during the weekends and long holidays. It is a large house with a pool of water supplied by a stream. Beside the pool, the water from the stream was channeled into open channels to form a shower. During the inspection of the country house, researchers at the Research Center Rene Rachou (CPqRR) - Oswaldo Cruz Foundation, at the Brazilian Ministry of Health detected that the place did not have basic sanitation. All the water used was damped, discarded in a dam located near the house. Out of forty-two individuals who were in the country house, thirty-eight participated in the study and were previously evaluated. After a preliminary assessment, we found that nineteen infected patients had been treated previous to our evaluation and five patients did not fulfill the inclusion criteria described below. Therefore, these patients were excluded from the study apart from other four subjects who had negative stool examination for S. mansoni. Thus, the group of patients evaluated was composed by ten individuals, five women and five men, aging 14 to 31 years, with parasite load ranging from 8 to 768 eggs per gram of feces (epg).

To participate in the study, patients in the acute phase of schistosomiasis have fulfilled the following criteria for inclusion: age between 10 and 65 years; did not report having received any treatment with anti-helminthic drugs in the last 24 months; diagnosis of acute schistosomiasis mansoni based on epidemiological data (recent contact with S. mansoni cercariae-contaminated water), clinical symptoms (acute enterocolitis, nausea, vomiting, abdominal pain, fever, headache, weight loss, cough, cercarial dermatitis, hepatomegaly and splenomegaly) and laboratory data (eosinophilia and viable S. mansoni 
eggs in stool). Each volunteer or their legal guardian signed their informed consent. In addition, we also excluded from this study all patients who had one of the following conditions: unable to hold examinations proposed; alcoholism, defined as above average weekly consumption of 420 grams of ethanol (daily average over $60 \mathrm{~g}$ of ethanol) [24]; pregnancy, defined by laboratory criteria; significant anemia defined as hemoglobin less than $10 \mathrm{~g} / \mathrm{dl}$ [25] and any other significant systemic disease, acute or chronic, that could interfere with the results of the proposed methods.

After blood collection, all patients who had positive stool examination for S. mansoni, regardless of participation in the study, were submitted to treatment with the standard Brazilian dose of Praziquantel (50-60 mg/kg).

A group of healthy volunteers formed by nine individuals, one woman and eight men aged 25 to 42 years, blood donors of the blood bank of Hospital Felicio Rocho, Belo Horizonte, Minas Gerais, Brazil constituted a control group (CT). It is important to mention that these individuals were screened and selected after serological tests for negativity for Chagas disease, leishmaniasis, human immunodeficiency virus (HIV), hepatitis, and did not report previous infection with S. mansoni.

The study was carried out according to the National Health Council resolution 196/96, which regulates the research involving human beings, and was approved by the Ethics Committees of the Faculty of Medicine, Federal University of Minas Gerais, Oswaldo Cruz Foundation, and the Brazilian National Committee on Ethics in Research.

\subsection{Parasitological examination}

Parasitological examination was performed using the Kato-Katz method [26]. The presence and the number of $S$. mansoni eggs per gram of feces were determined through examination of six blades per one stool sample for each patient. The results are presented as the arithmetic mean of number of eggs. The Kato-Katz method is the method of choice to measure infection level and has been used extensively in epidemiological studies.

\subsection{Evaluation of clinical parameters}

All the individuals who came into contact with water contaminated by cercariae were subjected to a detailed history, performed by a physician of our team. The survey used during this study contained data referring to number of the protocol, name, gender, age, education and place of birth and questions about the clinical symptoms/signs such as fever, diarrhea, nausea, vomiting, abdominal pain, cough, weight loss, headache, asthenia, facial edema and cercarial dermatitis.

\subsection{Evaluation of hematological parameters}

Peripheral blood was collected in $5 \mathrm{~mL}$ vacuum tubes containing ethylenediamine tetraacetic acid (EDTA) as anticoagulant (Vacutainer, Beckton Dickinson, CA, USA), approximately 40 days after contact with contaminated water by cercariae and only once prior to treatment with 
praziquantel. The hemograms were performed in automated hematological electronic counter (Coulter MD18, E.U.A). The parameters measured were hemoglobin, number of erythrocytes and hematocrit values as well as total and differential counts of leukocytes including absolute counts of eosinophils, neutrophils, lymphocytes and monocytes.

\subsection{Total IgE measurement}

The plasma levels of total IgE antibodies were quantified using Colorimetric Immunoenzymatic kit (SYM Total IgE, Symbiosis Diagnostic, Brazil). Aliquots of $25 \mu \mathrm{L}$ of plasma and six standards (Reagent kit SYM Total IgE Symbiosis Diagnostic, Brazil) at concentrations of $0,5,25,50,150$ and $400 \mathrm{UI} / \mathrm{mL}$ were dispensed in duplicates in wells of flat-bottomed plates, previously sensitized with streptavidin, together with $100 \mu \mathrm{L}$ of monoclonal antihuman IgE conjugated to biotin (Reagent kit SYM Total IgE Symbiosis Diagnostic, Brazil). The plates were incubated for 30 minutes at room temperature in the dark and washed five times with $300 \mu \mathrm{L} /$ well of wash solution (Reagent kit SYM Total IgE Symbiosis Diagnostic, Brazil). Subsequently were added $100 \mu \mathrm{L}$ of a second monoclonal antihuman IgE conjugated to peroxidase. The plates were incubated for 30 minutes at room temperature, in the dark, and washed five times with $300 \mu \mathrm{L} /$ well of wash solution. Then, $100 \mu \mathrm{L}$ of chromogen-substrate solution (tetramethylbenzidine-TMB) (Reagent kit SYM Total IgE Symbiosis Diagnostic, Brazil) were added by well, and the plate was incubated for 15 minutes in the dark. The reaction was stopped by adding $100 \mu \mathrm{L}$ of $1 \mathrm{~N}$ sulfuric acid (H2SO4) per well (Reagent kit SYM Total IgE Symbiosis Diagnostic, Brazil). The optical density of samples and standards was measured in an automatic reader (Molecular Devices Versa Max, California, USA) using a $450 \mathrm{~nm}$ filter.

\subsection{Nitric oxide plasma levels}

The plasma levels of nitric oxide were quantified using Immunoenzymatic kit QuantiChromTM Nitric Oxide (Quantitative Colorimetric Determination of Nitric Oxide, BioAssay Systems, USA). The assays were performed according to the manufacturer's recommendations. The deproteination of samples was made by adding $80 \mathrm{~mL}$ of zinc sulfate (ZnSO4) $75 \mathrm{mM}$ final concentration and $120 \mathrm{~mL}$ of sodium hydroxide $(\mathrm{NaOH}) 55 \mathrm{mM}$ final concentration. Samples were centrifuged at $400 \mathrm{~g}$ for 5 minutes at $4^{\circ} \mathrm{C}$. Then $70 \mathrm{~mL}$ of glycine buffer was added in each sample. Afterwards, aliquots of $100 \mu \mathrm{L}$ of plasma and eight standards at concentrations of 0 , $5,10,15,20,30,40$ and $50 \mu \mathrm{M} \mathrm{mL}$ were dispensed in duplicates in $1.5 \mathrm{~mL}$ tubes. Then, samples were placed in the presence of cadmium activated with $200 \mathrm{~mL}$ of Buffer Activation and incubated for 15 minutes. The samples were transferred in duplicates to their respective wells in flat-bottomed plates and added to $50 \mathrm{~mL}$ of reagents A and B. The optical density of samples and standards was measured in an automatic reader (Molecular Devices Reader-Precision, USA) using a $540 \mathrm{~nm}$ filter.

\subsection{Evaluation of hepatic enzymes}

For the analysis of hepatic functions for the study group, plasma concentration of the enzymes ALT (alaline amino transferase), AST (aspartate amino transferase) and $\gamma$-GT 
(gamma-glutamyl transferase) were quantified by kinetic method using ALT/GPT Liquiform, AST/GOT Liquiform and GAMA GT Liquiform kits (Labtest Diagnostic, Brazil) in the device Wiener Lab Metrolab 2300 plus (Model CM-200). The results were expressed in $\mathrm{UI} / \mathrm{mL}$.

\subsection{Ultrasonographic analysis}

Ultrasonographic evaluation was performed using a Nemio SSA/550 a machine (Toshiba, Town, Japan) with a $3-\mathrm{MHz}$ sector probe for patients $\geq 10$ years old and a $5-\mathrm{MHz}$ probe for patients under 10 years old. The group of healthy individuals non-infected with $S$. mansoni (CT group) consisted of twelve volunteers, paired by sex and age with the infected patients. Seven acute patients, three women and four men aged 14 to 31 years old have had ultrasonographic evaluation. All study population was examined by the same physician (MCBA). Liver size, portal-vein diameter, thickness of the central walls and peripheral portal branches, spleen size and splenic vein diameters were assessed as described $[27,28]$. The liver was also examined for surface smoothness. Portal vein diameter was measured at its entrance into the liver and its bifurcation inside the liver. The spleen was evaluated by using oblique and longitudinal scanning of the left upper quadrant. The gallbladder was examined for wall thickness and stones. The periportal thickness was evaluated according to previous established criteria by [27-29].

\subsection{Statistical analysis}

The statistical analysis of the data was made through GraphPad PRISM® 5.00 software release for Windows (La Jolla, CA, USA). Student's t test was used for parametric data comparison between two groups, while for non-parametric data we used the Mann-Whitney test. In all cases, the data were considered significant at $\mathrm{P}<0.05$.

\section{Results}

\subsection{Demographic data and intensity of S. mansoni infection}

Out of forty-two people who were present in the country house, thirty-eight (90.5\%) participated in this study and reported contact with water contaminated with cercariae. Out of these, thirty-four (89.5\%) had eggs of S. mansoni in their feces and four $(10.5 \%)$ were repeatedly negative. According to criteria previously mentioned, twenty-four patients were excluded from the study and ten patients were considered to be on an ongoing acute phase of schistosomiasis. In the acute group (ACT), there were no significant differences in age between females and males $(23.0 \pm 7.8$ and $19.8 \pm 4.5$ years old, respectively, $\mathrm{p}$ value $=0.45)$ and the intensity of infection did not differ regarding gender, $(205.6 \pm 318.5$ and $98.4 \pm 70.7 \mathrm{eggs} / \mathrm{g}$ of feces, respectively, $\mathrm{P}$ value $=0.50$ ). The ACT group presented parasite load ranging from 8 to 768 eggs per gram of feces $(152.0 \pm 224.7)$. 


\begin{tabular}{|c|c|c|c|}
\hline \multirow{2}{*}{ Parameter } & \multicolumn{3}{|c|}{ Subjects } \\
\hline & Total individuals & Evaluated individuals & Acute patients \\
\hline Number of subjects (\%) & $42(100 \%)$ & 38 (90.5\%) & $10(23.8 \%)$ \\
\hline \multicolumn{4}{|l|}{ Age } \\
\hline Range & $01-65$ & $01-65$ & $14-31$ \\
\hline Mean \pm SD & $22.4 \pm 15.2$ & $22.5 \pm 15.5$ & $21.4 \pm 6.2$ \\
\hline Median & 21.5 & 20.5 & 22.5 \\
\hline \multicolumn{4}{|l|}{ Gender } \\
\hline Female & $25(59.5 \%)$ & $22(57.9 \%)$ & $05(50.0 \%)$ \\
\hline Male & $17(40.5 \%)$ & $16(42.1 \%)$ & $05(50.0 \%)$ \\
\hline \multicolumn{4}{|c|}{ Parasitological Examination } \\
\hline Negative & --- & $04(10.5 \%)$ & 0 \\
\hline Positive & ---- & $34(89.5 \%)$ & $10(100 \%)$ \\
\hline \multicolumn{4}{|c|}{ Egg counts (eggs/g of feces) } \\
\hline Range & --- & $0-768$ & $8-768$ \\
\hline Mean \pm SD & --- & $50.8 \pm 132.2$ & $152.0 \pm 224.7$ \\
\hline Median & --- & 10.0 & 86.0 \\
\hline
\end{tabular}

Table 1. Characterization of the study population

\subsection{Clinical manifestations}

The magnitude of clinical manifestations of schistosomiasis varies from light to severe intensity. Two patients showed serious clinical symptoms and required hospitalization due to the severity of the disease. The patients reported the onset of symptoms 20-30 days after water exposure. Headache and fever $(60.0 \%$ and $50.0 \%$, respectively) were the most common symptoms among patients, followed by diarrhea and weight loss (both $40.0 \%$ ). Other clinical symptoms/signals were also recorded such as nausea/vomiting, abdominal pain, cough, asthenia, facial edema (each one with frequency of $30.0 \%$ ) as well as urticaria and cercarial dermatitis (both $10.0 \%$ ).

Table 2 highlights the main features observed in different human studies evaluating acute phase of schistosomiasis mansoni performed in distinct brazilian states such as Pernambuco, 
Sergipe and Minas Gerais. Although in these studies the frequency of exposed/infected individuals was similar ranging $90-100 \%$ and the incubation period has also occurred in comparable times such 20-30 days, we have observed strongly heterogeneous symptoms between them. Nonetheless, our study demonstrated some similar clinical symptoms in comparison to those found by Barbosa et al. 2001b [30] like the frequency of fever $(50.0 \%$ and $54.0 \%$, respectively), cough $(30.0 \%$ and $33.0 \%$, respectively) and urticaria $(10.0 \%$ and $8.0 \%$, respectively). However, other parameters presented distinct results like the frequency of headache $(60.0 \%$ and $33.0 \%$, respectively) and diarrhea ( $40.0 \%$ and $25.0 \%$, respectively).

\begin{tabular}{|c|c|c|c|c|}
\hline Parameters & $\begin{array}{c}\text { Barbosa Et Al. } \\
\text { 2001a [15] }\end{array}$ & $\begin{array}{c}\text { Barbosa Et Al. } \\
2001 \mathrm{~b}[30]\end{array}$ & $\begin{array}{c}\text { De Jesus Et Al. } \\
2002[16]\end{array}$ & This Study \\
\hline Number of patients & 11 & 12 & 31 & 10 \\
\hline \multirow{2}{*}{ Site/State } & Ilha de Itamaracá & Escada & Aracaju & Igarapé \\
\hline & Pernambuco & Pernambuco & Sergipe & Minas Gerais \\
\hline Exposed/infected & $92 \%$ & $100 \%$ & $92 \%$ & $90 \%$ \\
\hline $\begin{array}{l}\text { Incubation period } \\
\text { (days) }\end{array}$ & $15-30$ & 20 & $20-30$ & $20-30$ \\
\hline Headache & $36 \%$ & $33 \%$ & $87 \%$ & $60 \%$ \\
\hline Fever & $100 \%$ & $54 \%$ & $90 \%$ & $50 \%$ \\
\hline Diarrhea & $64 \%$ & $25 \%$ & $81 \%$ & $40 \%$ \\
\hline Cough & $91 \%$ & $33 \%$ & $91 \%$ & $30 \%$ \\
\hline Abdominal pain & $64 \%$ & N.E. & $93 \%$ & $30 \%$ \\
\hline Urticaria & $18 \%$ & $08 \%$ & N.E. & $10 \%$ \\
\hline Cercarial dermatitis & $100 \%$ & N.E. & N.E. & $10 \%$ \\
\hline Hepatomegaly & $75 \%$ & N.E. & $35 \%$ & $86 \%$ \\
\hline $\begin{array}{l}\text { Transaminases } \\
\text { (increase) }\end{array}$ & $36 \%$ & N.E. & $38 \%$ & N.L. \\
\hline \multicolumn{5}{|l|}{ N.E. - not evaluated } \\
\hline N.L. - normal levels & & & & \\
\hline
\end{tabular}

Table 2. Main features observed in different human studies evaluating the acute phase of schistosomiasis mansoni 


\subsection{Plasma levels of total IgE and nitric oxide}

The plasma levels of total IgE and nitric oxide from the ACT group are illustrated in Figure 1. The analysis of the results showed that the ACT group presented a significant $(P<0.05)$ increase of these parameters as compared with the CT group.

\subsection{Hematological profile}

The main findings related to the hematological profile from the ACT group are illustrated in Figures 2 and 3. The analysis showed a significant reduction in the concentration of hemoglobin in the ACT group as well as an increase in the total leukocytes count as compared with the CT group. Increased total leukocytes were reflected in the absolute values of lymphocytes and eosinophils also increased in the ACT group as compared with the CT group. No significant difference was found between these two groups regarding other analyzed parameters such as number of erythrocytes, percentage of hematocrit, and absolute values of neutrophils and monocytes.
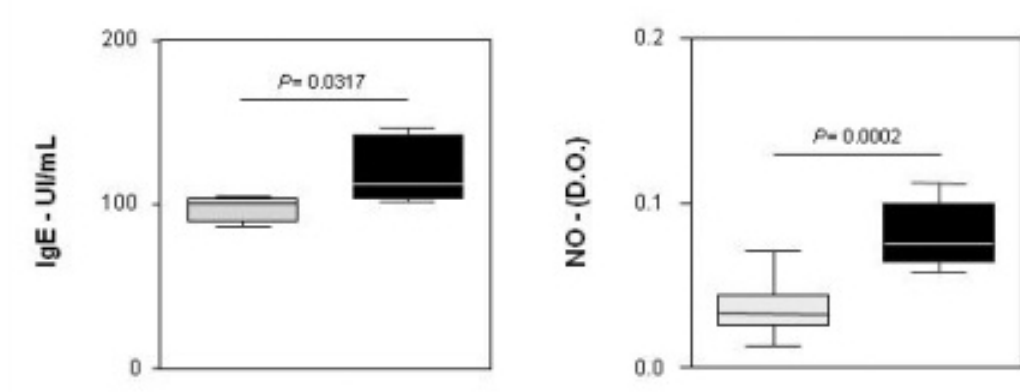

Figure 1. Total plasma IgE and nitric oxide (NO) levels in acute schistosomiasis patients ( $A C T=10)$ and non-infected individuals $(C T=09)$. The results are expressed in box-plot format. The box stretches from the lower hinge (defined as the 25th percentile) to the upper hinge (the 75th percentile) and therefore contains the middle half of the scores in the distribution. The median is shown as a line across the box. Therefore $1 / 4$ of the distribution is between this line and the top of the box and $1 / 4$ of the distribution is between this line and the bottom of the box. Significant differences (connecting lines) were considered at $P<0.05$. 


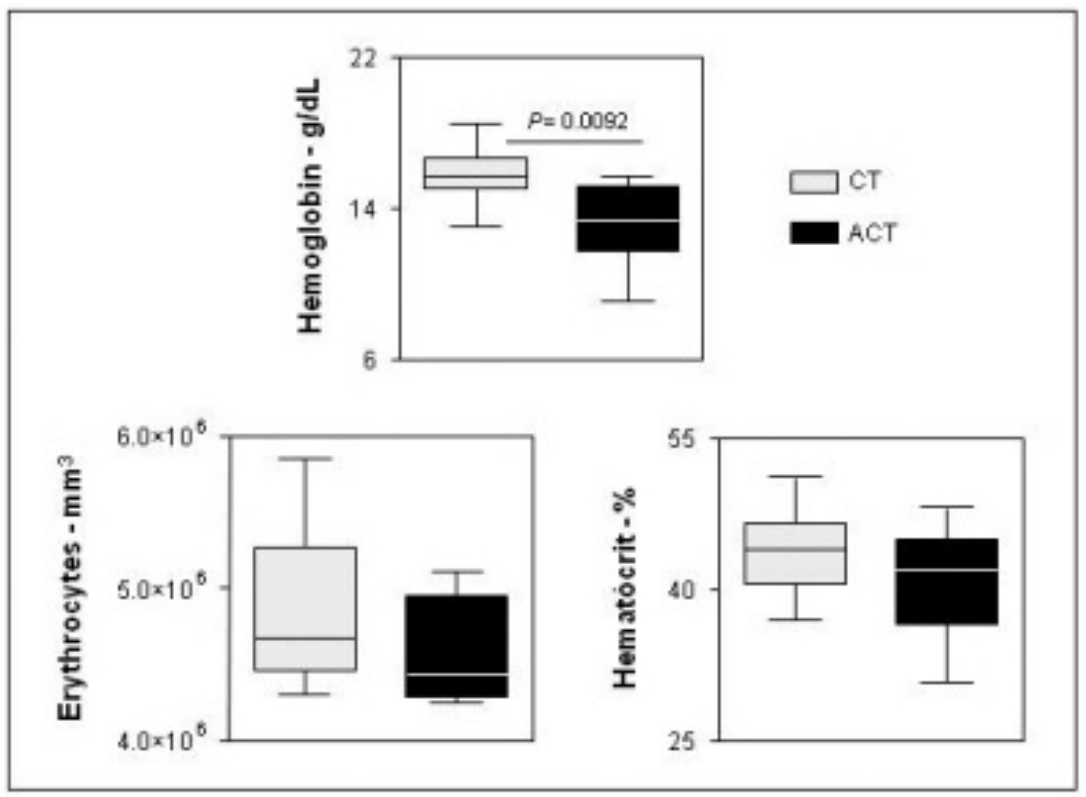

Figure 2. Hematological profile (hemoglobin-g/dL, erythrocytes $/ \mathrm{mm}^{3}$ and percentage of hematocrit) from acute schistosomiasis patients $(A C T=10)$ and non-infected individuals $(C T=09)$. The results are expressed in box-plot format. The box stretches from the lower hinge (defined as the 25th percentile) to the upper hinge (the 75th percentile) and therefore contains the middle half of the scores in the distribution. The median is shown as a line across the box. Therefore $1 / 4$ of the distribution is between this line and the top of the box and 1/4 of the distribution is between this line and the bottom of the box. Significant differences (connecting lines) were considered at $P<0.05$. 


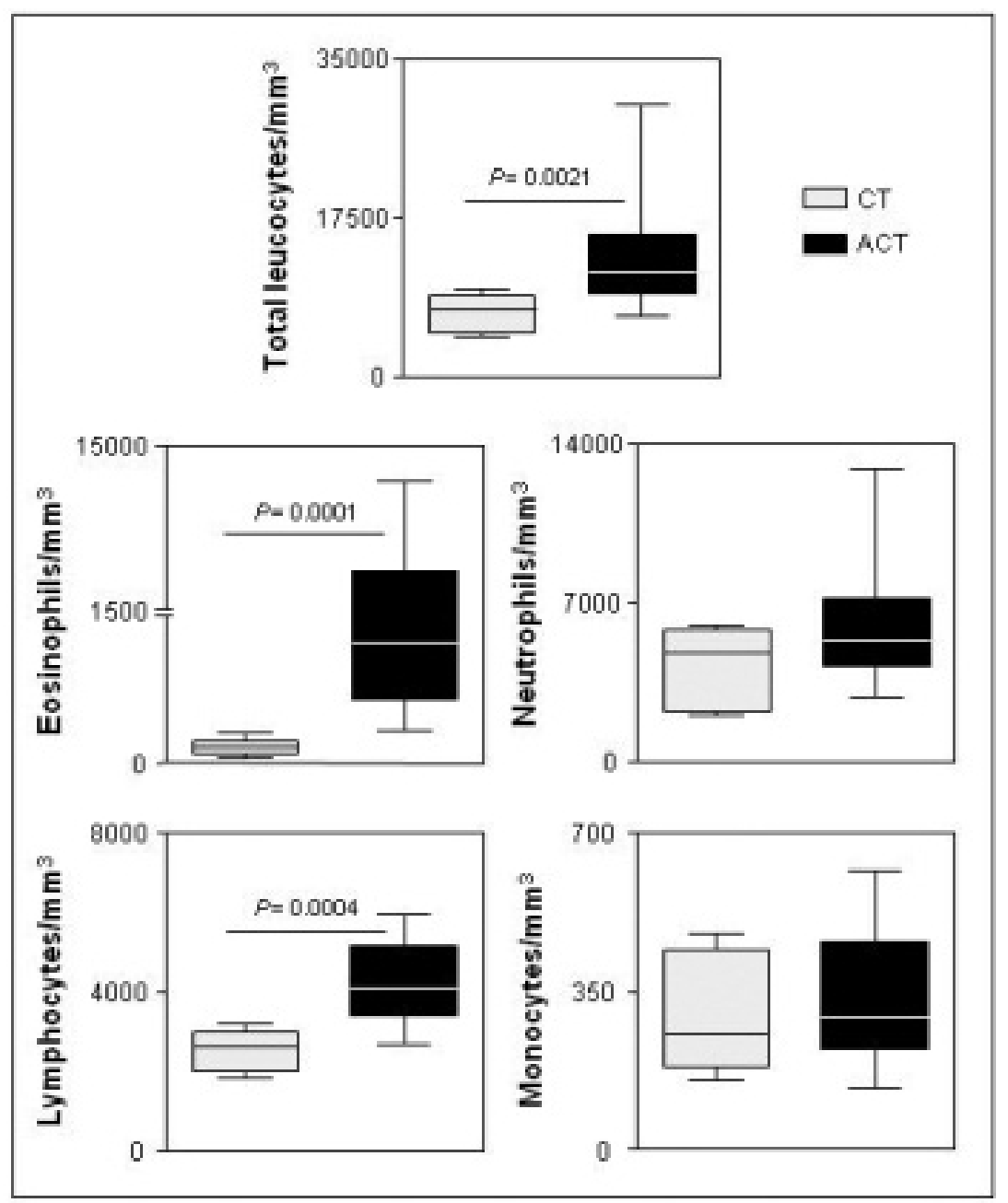

Figure 3. Total and differential leukocyte counts from acute schistosomiasis patients $(A C T=10)$ and non-infected individuals $(C T=09)$. The results are expressed in box-plot format highlighting the gap of $50 \%$ of data set measurement for absolute values in $\mathrm{mm}^{3}$ of each leukocyte subset analyzed. Significant differences (connecting lines) were considered at $P<0.05$.

\subsection{Profile of hepatic enzymes}

Acute patients presented levels of ALT, AST and $\gamma$-GT enzymes similar to reference values and there were no significant differences between these levels and those presented by CT group. (Table 3). 


\begin{tabular}{lcc}
\hline \multicolumn{1}{c}{ Hepatic Enzymes } & $\begin{array}{c}\text { Control Group } \\
(\mathbf{N}=\mathbf{9})\end{array}$ & $\begin{array}{c}\text { Acute Patients } \\
\mathbf{( N = 8 )}\end{array}$ \\
\hline $\begin{array}{l}\text { ALT (alaline amino transferase) } \\
(3-50 \mathrm{U} / \mathrm{mL})^{*}\end{array}$ & $12.5 \pm 11.2$ & $8.6 \pm 5.5$ \\
\hline AST (aspartate amino transferase) & $18.7 \pm 5.9$ & $23.0 \pm 6.7$ \\
$(12-46 \mathrm{U} / \mathrm{mL})^{*}$ & $23.4 \pm 9.9$ & $33.9 \pm 16.6$ \\
\hline $\mathrm{Y}$-GT (gamma-glutamyl transferase) & & \\
$(9-61 \mathrm{U} / \mathrm{L})^{*}$ & & \\
\hline Values are represented as mean \pm standard deviation & & \\
${ }^{*}$ Reference values & & \\
\hline
\end{tabular}

Table 3. Hepatic serological tests in the study group

\subsection{Ultrasonographic analysis}

The results demonstrated that the ACT group presented some significant differences as compared with the CT group: medium increase in the measurement (in $\mathrm{mm}$ ) of longitudinal left/right lobe of liver (117.4 \pm 19.7 and $99.0 \pm 12.3$ or $150.1 \pm 18.2$ and $102.2 \pm 16.0$, respectively), size of longitudinal spleen (110.6 \pm 16.3 and $91.2 \pm 12.7$, respectively) as well as dimension of Hilar portal vein wall ( $3.4 \pm 1.0$ and $1.5 \pm 0.3$, respectively) (Table 4$)$. Periportal lymph node enlargement was observed in six of seven patients (85.7\%). The periportal lymph nodes were larger, round or ovoid in shape and sharply defined with thin halos surrounding hypoechoic areas (Figure 4). An additional ultrasonographic feature observed was an incipient periportal echogenic thickening named as grade I fibrosis (Figure 5).

\begin{tabular}{lcc}
\hline \multicolumn{1}{c}{ Site Of Measurement } & $\begin{array}{c}\text { Control Group } \\
(\mathbf{N}=\mathbf{1 2})\end{array}$ & $\begin{array}{c}\text { Acute Patients } \\
(\mathbf{N}=\mathbf{7})\end{array}$ \\
\hline Longitudinal left lobe of liver & $99.0 \pm 12.3$ & $117.4 \pm 19.7^{*}$ \\
\hline Anteroposterior left lobe of liver & $46.7 \pm 10.0$ & $53.3 \pm 10.9$ \\
\hline Longitudinal right lobe of liver & $102.2 \pm 16.0$ & $150.1 \pm 18.2^{*}$ \\
\hline Anteroposterior right lobe of liver & $68.6 \pm 11.9$ & $63.4 \pm 9.6$ \\
\hline Longitudinal spleen & $91.2 \pm 12.7$ & $110.6 \pm 16.3^{*}$ \\
\hline Anteroposterior spleen & $35.1 \pm 6.3$ & $43.5 \pm 11.1$ \\
\hline Portal vein & $10.0 \pm 1.2$ & $3.9 \pm 1.9$ \\
\hline Hilar portal vein wall & $1.5 \pm 0.3$ & $7.1 \pm 1.4$ \\
\hline Splenic vein & $6.4 \pm 1.3$ & $1.8 \pm 1.0^{*}$ \\
\hline Superior mesenteric vein & $6.7 \pm 1.1$ & $\mathrm{~N} . \mathrm{V}$. \\
\hline Periportal lymph node & & \\
\hline Values are represented in mm as mean \pm standard deviation & & \\
* Statistical difference $(p<0.05)$ & & \\
N.V. - not visualized (normal abdominal lymph nodes are usually not visualized by sonography) & \\
\hline
\end{tabular}

Table 4. Ultrasonographic features of the study group 
(a)

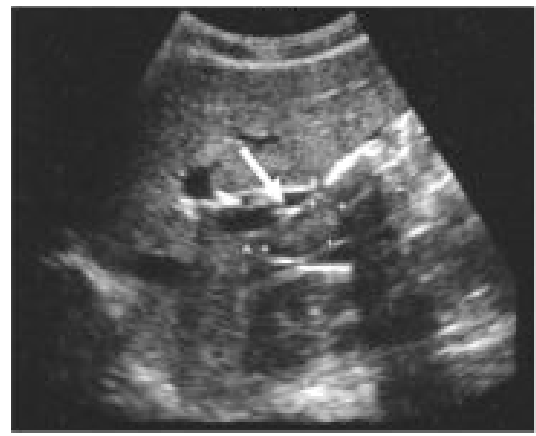

(b)

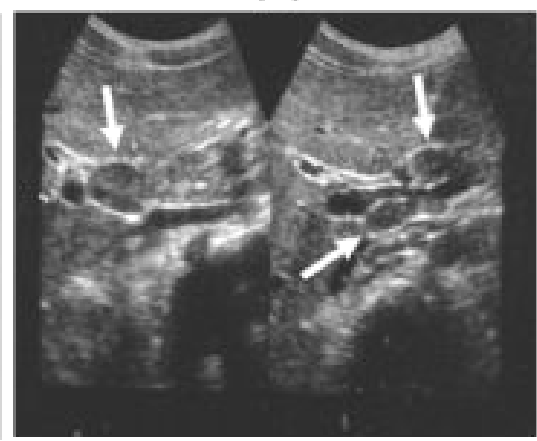

Figure 4. Representative ultrasonographic images of periportal lymph nodes from acute schistosomiasis patients. The arrows indicate larger lymph nodes, ovoid in shape (a) and rounded (b) with thin halos surrounding hypoechoic areas. Ultrasonographic analysis was performed with a Nemio SSA/550a machine (Toshiba).

(a)

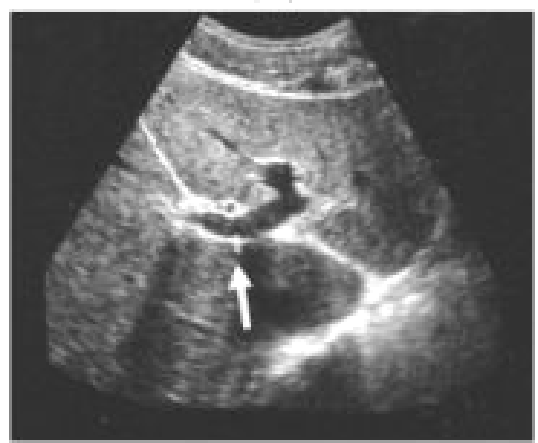

(b)

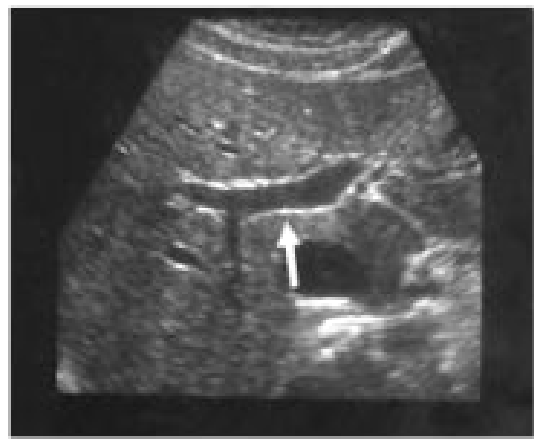

Figure 5. Representative ultrasonographic images of liver from acute schistosomiasis patient (a) and healthy volunteer (b). The arrows indicate incipient periportal echogenic thickening (a) and no periportal echogenic thickening (b). UItrasonographic analysis was performed with a Nemio SSA $/ 550^{a}$ machine (Toshiba).

\section{Discussion}

The transmission of S. mansoni may vary depending on the ecology of the disease and the social standing of the population in which it occurs. The prevalence and intensity of the infection is subject to cultural practices, specific for each locality or situation and usually associated to economic, domestic or leisure activities [15, 31].

During the last decades, the traditional epidemiological pattern showed a tendency to change. Accelerating migration from the countryside to cities threatened to overwhelm 
existing water and sanitation systems, and to increase urban schistosomiasis [9, 32, 33]. In Brazil, especially in urban areas, acute schistosomiasis outbreaks were observed and documented with a certain frequency $[9,14,15,17,34-36]$. The increase of acute schistosomiasis cases also indicates that a non-immune fraction of the population became exposed to the disease $[9,10,36]$.

The incidence of the acute form of schistosomiasis mansoni is certainly underestimated. This illness has been mainly described as a disease of travelers. Many scientific publications concerning this acute disease refer to groups of tourists, fishermen or sailors originally from a non-endemic country who have visited a tropical zone [17, 37, 38]. However, as schistosomiasis is a focally distributed infection $[17,39,40]$, the acute form is also diagnosed in inhabitants from endemic countries who do not live in endemic areas. Nevertheless, acute disease is seldom recognized in infected patients from endemic areas. According to Lambertucci [41], acute schistosomiasis is most evident in primary infection in non-immune individuals. Among people living in endemic areas, the acute phase may pass undiagnosed. Because in endemic areas exposure to infection occurs early in life, symptoms would be inconspicuous and diagnosis not even suspected.

The clinical features of the acute phase of schistosomiasis mansoni present a wide spectrum $[42,43]$ and the relative contribution of host and parasite factors in the pathogenesis of the disease is not completely elucidated [20, 43-45]. According to Neves [46], the clinical forms of the disease will depend on the interaction of at least three sequential events: (a) the evolution phase of the worms, whether before or after oviposition and the deposition of eggs in the tissues; (b) the organ predominantly involved by young or mature worms and by their eggs; and (c) the type and the qualitative/quantitative deviation of the total and local host response to antigenic products derived from the disintegration of schistosomula, adult worms and their eggs.

The main clinical findings presented in our study such as headache, fever, diarrhea and weight loss were consistent with those found by other authors [9, 15-17]. Different intensities of clinical manifestation are observed in patients with acute schistosomiasis, some of them evolved with a relatively severe picture while others with mild symptoms. In our study, we have also observed a similar profile.

The development of non-apparent clinical form characterized by blood eosinophilia and a positive immediate cutaneous reaction in the initial phase of the $S$. mansoni infection was described by Rocha et al. [47]. According to previous data in the literature [13, 15, $16,43]$, patients with acute phase of schistosomiasis in our study had an increased absolute number of eosinophils in comparison to reference data ranging between 400 to 600 cells $/ \mathrm{mm}^{3}$ [48]. Eosinophils are thought to play a major role in a variety of human diseases, including allergic inflammation, malignancy, and host defense against helminth infections. However, the exact role(s) of eosinophils in schistosomiasis regarding immunopathology remains unclear. Eosinophils may participate in Ab-dependent protective immune responses [49]. Human eosinophils express IgE receptors that participate in an IL-5-dependent Ab-dependent cell-mediated cytotoxicity reaction against schistosomula in vitro. Eosinophils also mediate the destruction of miracidia and schistosome eggs 
[50]. Experimental studies have shown that the eosinophilia would be induced by type 2cytokines as interleukin (IL)-4, IL-9, IL-13 and mainly by IL-5 [51]. According to Rocha et al. [43], the eosinophilia may be considered a possible pathogenic factor in acute schistosomiasis. The specific granules of the eosinophil contain lysosomal hydrolases as well as several cationic proteins like the major basic protein (MBP) [43, 52], the eosinophil cationic protein $(\mathrm{ECP})$ and a neurotoxin, the eosinophil-derived neurotoxin (EDN), besides a peroxidase $[43,53]$. The MBP in low concentrations is toxic to schistosomula but this action is non-selective since mammalian cells can also be damaged [43, 54, 55]. Both peroxidase and ECP are also toxic for helminths and mammal cells [43, 56, 57]. The cytolysis or eosinophil degranulation with the release of granule proteins can contribute to the genesis of local pathological alterations causing dysfunction or damage to the cells, especially when a great number of eosinophils are involved [43, 53, 58].

According to this report, acute patients presented increased plasma levels of $\operatorname{IgE}$ and nitric oxide as compared with the CT group. Our result is similar to the data published by De Souza et al. [59], which evaluated the humoral immune response through quantifying of the total IgE levels from patients with acute clinical form of schistosomiasis. Thus, we suggest that total IgE may be related to disease morbidity, as established by Pereira et al. [60]. Nitric oxide (NO) has been identified as an important cytotoxic factor and versatile messenger in the immune system being responsible to induce both anti- and/or proinflammatory effects [61]. There are broad direct and indirect evidences that NO can act as an anti-schistosomal and antiparasitic molecule [62-64]. Moreover, NO produced by human leukocytes has been shown to kill larval schistosome parasites [64, 65]. Studies in experimental models of acute schistosomiasis showed that the inhibition of iNOS resulted in cachexia and exacerbated hepatic pathology, suggesting that in schistosomiasis, NO limits hepatocyte damage [66-68].

From two to eight weeks after a first contact with natural water infested by Schistosoma cercariae, susceptible infected patients may present a syndrome comprising a period of 2 to 30 days of fever, diarrhea, toxemia and weakness, weight loss, abdominal pain, cough, mialgya, and arthralgia, edema, urticaria, nausea/vomiting and hepatosplenomegaly [7]. Until recently, acute schistosomiasis diagnosis was only based on epidemiological and clinical features, presence of S. mansoni eggs in stools and eosinophilia. However, the diagnosis becomes a challenge to the physicians due to the non-specificity symptoms as well as the lack of positivity of the subjects for S. mansoni eggs in feces in earlier stage of the infection. In this context, abdominal ultrasound can be a complementary tool to assist the diagnoses of the $S$. mansoni infection. The ultrasonographic findings presented in this study were consistent with those described by Barata et al. [11]. According to this report, ultrasonographic evaluation showed non-specific increase in the size of liver, incipient periportal echogenic thickening, in addition to lymph nodes easily identified in the periportal region. The authors have also performed a histological liver analysis from hepatic biopsies of three patients, and the data demonstrated that the periportal thickening seen on ultrasound was probably produced by inflammatory infiltration of the portal tracts caused by schistosomiasis, which disappeared after treatment with oxamniquine. 
However, liver biopsy is an invasive procedure that is seldom justified. It is important to mention that the ultrasonographic features of the lymph nodes, liver and spleen in acute schistosomiasis, although highly sensitive, are not pathognomonic of acute schistosomiasis, and are also seen in other infectious diseases such as acute hepatitis and other viral diseases [19, 69, 70].

Normal abdominal lymph nodes are usually not visualized by sonography. Neoplastic lymph nodes are generally rounded and hypoechoic, sometimes with an irregular shape and borders [19, 71, 72]. Lymphomas can also affect periportal and peripancreatic lymph nodes, but there is generally an extensive involvement of other abdominal lymph nodes, mainly retroperitoneal, that is almost anechoic and usually rounded. In this circumstance, the liver and spleen are enlarged and can show focal lesions [19, 72]. Patients with acquired immunodeficiency syndrome (AIDS) can also show hepatoesplenomegaly and abdominal lymphadenopathy, but the echogenicity of the liver is usually increased. Tumors related to AIDS, such as Kaposi's sarcoma, have also been reported as a cause of lymphadenopathy [73]. Mesenteric and periportal lymphadenomegaly is a common finding in blastomycosis and these are almost anechoic [19].

In the current study, we have also evaluated the liver function of acute schistosomiasis patients by the ALT, AST and $\gamma$-GT assessment. Comparing with other studies in literature $[15,16]$, we did not observe changes in any of the enzymes evaluated, suggesting that the hepatocellular function is preserved or minimally compromised in the study population. In patients presenting intestinal or hepatointestinal clinical form of schistosomiasis,it has been observed that the liver function is maintained. In those patients showing the hepatosplenic form, liver function related to protein metabolism was in general changed, but rarely this function is compromised in a broad spectrum. Only after repeated blood spoliation, in the terminal stage of illness, there is strong involvement of the liver parenchymal. According to some authors, when liver cell damage occurs there is an increase of ALT and AST levels, but in the S. mansoni infection this type of injury is not commonly observed [74, 75]. On the other hand, the most important cause of increased

$\gamma$-GT levels is the chronic stimulation of the microsomal fraction of hepatocytes and the presence of cholestasis [76]. According to Martins \& Borges [77], the chronic stimulation of the microsomal occurs only in patients with hepatosplenic form of schistosomiasis. Kardorff et al. [74] observed that the increase of $\gamma$-GT occurs only in patients with severe periportal fibrosis, irregular texture liver and collateral vessels.

\section{Conclusion}

In conclusion, the data presented here suggest that alterations identified by analyses of clinical/ laboratorial parameters and ultrasonographic features, although not specific, are compatible with the acute phase of Schistosomiasis mansoni and provide a reliable complementary tool for the diagnosis of the infection. 


\section{Acknowledgements}

This work was supported by grants from Oswaldo Cruz Foundation (FIOCRUZ), Conselho Nacional de Desenvolvimento Científico e Tecnológico (CNPq), Fundação de Amparo à Pesquisa de Minas Gerais (FAPEMIG), and UNDP World Bank/WHO Special Program for Research and Training in Tropical Diseases. The authors are grateful to the technical staff at the Laboratory of Cellular and Molecular Immunology and the Laboratory of Biomarkers of Diagnosis and Monitoring, Oswaldo Cruz Foundation, Brazil for their invaluable assistance during this study. The authors also thank the Program for Technological Development in Tools for Health - PDTIS - FIOCRUZ for the use of its facilities. OAMF, PMZC, RCO, GG, and ATC are grateful for the CNPq fellowships.

\section{Author details}

Matheus Fernandes Costa-Silva ${ }^{* * 1,2}$, Denise da Silveira-Lemos ${ }^{* * 1,2,3}$,

Amanda Cardoso de Oliveira Silveira ${ }^{1}$, Pedro Henrique Gazzinelli-Guimarães ${ }^{2}$,

Helena Barbosa Ferraz ${ }^{1}$, Cristiano Lara Massara ${ }^{4}$, Martin Johannes Enk ${ }^{5}$,

Maria Carolina Barbosa Álvares ${ }^{6}$, Olindo Assis Martins-Filho ${ }^{1}$, Paulo Marcos Zech Coelho ${ }^{5}$, Rodrigo Corrêa-Oliveira ${ }^{1,7}$, Giovanni Gazzinelli ${ }^{2}$ and Andréa Teixeira-Carvalho ${ }^{1,2,7^{*}}$

*Address all correspondence to: andreat@cpqrr.fiocruz.br

1 Laboratory of Biomarkers of Diagnosis and Monitoring, Research Center Rene Rachou, FIOCRUZ, Belo Horizonte, MG, Brazil

2 Laboratory of Immunology Cellular and Molecular, Research Center Rene Rachou, FIOCRUZ, Belo Horizonte, MG, Brazil

3 Laboratory of Immunoparasitology, Department of Biological Science, Institute of Exact Sciences and Biological/NUPEB, Federal University of Ouro Preto, MG, Brasil

4 Laboratory of Helminthology and Medical Malacology, Research Center Rene Rachou, FIOCRUZ, Belo Horizonte, MG, Brazil

5 Laboratory of Schistosomiasis, Research Center Rene Rachou, FIOCRUZ, Belo Horizonte, MG, Brazil

6 Holy House of Mercy of Belo Horizonte, Belo Horizonte, MG, Brazil

7 National Institute of Science and Technology in Tropical Diseases - INCT-DT- Salvador, BA, Brasil

**The authors contributed equally to this study 


\section{References}

[1] World Health Organization (WHO)First report of joint WHO Expert Committees on the Prevention and Control of Schistosomiasis and Soil-transmitted Helminthiasis. Technical Report Series, Geneva. (2002).

[2] Wilson, M. S, Mentink-kane, M. M, Pesce, J. T, Ramalingam, T. R, Thompson, R, \& Wynn, T. A. Immunopathology of schistosomiasis. Immunology Cell Biology (2007). , 85, 148-154.

[3] Passos, A. D, \& Amaral, R. S. Esquistossomose mansônica: aspectos epidemiológicos e de controle. Revista da Sociedade Brasileira de Medicina Tropical (1998). , 31, 61-74.

[4] Katz, N, \& Peixoto, S. V. Critical analysis of the estimated number of Schistosomiasis mansoni carriers in Brazil. Revista da Sociedade Brasileira de Medicina Tropical (2000). , 33, 303-308.

[5] Raso, P. Esquistossomose mansônica. In: Brasileiro Filho, G. Bogliolo patologia, Rio de Janeiro: Guanabara-Koogan; (2000).

[6] Katz, N. Schistosomiasis control in Brazil. Memórias do Instituto Oswaldo Cruz (1998). , 93, 33-35.

[7] Coura, J. R, \& Amaral, R. S. Epidemiological and control aspects of schistosomiasis in Brazilian endemic areas. Memórias do Instituto Oswaldo Cruz (2004). , 99, 13-19.

[8] Amaral, R. S, Tauil, P. L, Lima, D. D, \& Engels, D. An analysis of the impact of the Schistosomiasis Control Programme in Brazil. Memórias do Instituto Oswaldo Cruz (2006). , 101, 79-85.

[9] Enk, M. J, Amorim, A, \& Schall, V. T. Acute Schistosomiasis Outbreak in the Metropolitan Area of Belo Horizonte, Minas Gerais: Alert about the Risk of Unnoticed Transmission Increased by Growing Rural Tourism. Memórias do Instituto Oswaldo Cruz (2003). , 98, 745-750.

[10] Enk, M. J, Caldeira, R. L, Carvalho, O. S, \& Schall, V. T. Rural tourism as risk factor for the transmission of schistosomiasis in Minas Gerais, Brazil. Memórias do Instituto Oswaldo Cruz (2004). , 99, 105-108.

[11] Barata, C. H, Pinto-silva, R. A, \& Lambertucci, J. R. Abdominal ultrasound in acute schistosomiasis mansoni. British Journal of Radiology (1999). , 72, 949-952.

[12] Nguyen, L. Q, Estrella, J, Jett, E. A, Grunvald, E. L, Nicholson, L, \& Levin, D. L. Acute schistosomiasis in nonimmune travelers: chest CT findings in 10 patients. AJR American Journal Roentgenology (2006). , 186, 1300-1303.

[13] Gazzinelli, G, Lambertucci, J. R, Katz, N, Rocha, R. S, Lima, M. S, \& Colley, D. G. Immune responses during human schistosomiasis mansoni: XI. Immunologic status of 
patients with acute infections and after treatment. Journal of Immunology (1985). , $135,2121-2127$.

[14] Neves, J. Acute or toxemic form of mansoni's schistosomiasis (Forma aguda ou toxêmica da esquistossomose mansoni). Memórias do Instituto Oswaldo Cruz (1992). , 87, 321-324.

[15] Barbosa, C. S. Montenegro SML, Abath FG, Domingues AL. Specific situations related to acute schistosomiasis in Pernambuco, Brazil. Memórias do Instituto Oswaldo Cruz (2001a). , 96, 169-172.

[16] De Jesus, A. R, Silva, A, Santana, L. B, Magalhães, A, De Jesus, A. A, \& Almeida, R. P. Rego MAV, Burattini MN, Pearce EJ, Carvalho EC. Clinical and immunologic evaluation of 31 patients with acute schistosomiasis mansoni. The Journal of Infectious Diseases (2002). , 185, 98-105.

[17] Rabello ALTAcute human schistosomiasis mansoni. Memórias do Instituto Oswaldo Cruz (1995). , 90, 277-280.

[18] Lambertucci, J. R. Da Silva RA, Gerspacher-Lara R, Barata CH. Acute Manson's schistosomiasis: sonographic features. Transactions of the Royal Society of Tropical Medicine and Hygiene (1994). , 88, 76-87.

[19] Rabello ALTPinto-Silva RA, Rocha RS, Katz N. Abominal ultrasonography in acute clinical schistosomiasis mansoni. The American Journal of Tropical Medicine and Hygiene (1994). , 50, 748-752.

[20] Hiatt, R. A, Sotomayor, Z. R, Sanchez, G, Zambrana, M, \& Knight, W. B. Factors in the pathogenesis of acute schistosomiasis mansoni. The Journal of Infectious Diseases (1979). , 139, 659-666.

[21] Caldas, I. R, Campi-azevedo, A. C, Oliveira, L. F, Silveira, A. M, Oliveira, R. C, \& 25 Gazzinelli, G. Human schistosomiasis mansoni: immune responses during acute and 26 chronic phases of the infection. Acta Tropica (2008)., 108, 109-117.

[22] Oliveira, D. M, Gustavson, S, Silva-teixeira, D. N, \& Goes, A. M. Nitric Oxide and IL-10 Production Induced by PIII- A Fraction of Schistosoma mansoni Adult Worm Antigenic Preparation-Associated with Downregulation of In Vitro Granuloma Formation. Human Immunology (1999). , 60, 305-311.

[23] Oliveira, D. M, Silva-teixeira, D. N, Carmo, S. A, \& Goes, A. M. Role of nitric oxide on human schistosomiasis mansoni: up-regulation of in vitro granuloma formation by L-NAME. Nitric Oxide (1998). , 2, 57-62.

[24] Skinner, H. A, Holt, S, Schuller, R, Roy, J, \& Israel, Y. Identification of alcohol abuse using laboratory markers and a history of trauma. Annals of Internal Medicine (1984). , 101, 847-51. 
[25] Stoltzfus, R. J, \& Dreyfuss, M. L. Guidelines for the use of iron supplements to prevent and treat iron deficiency anemia. International Nutritional Anemia Consultative Group, Washington: (1998).

[26] Katz, N, Chaves, A, \& Pellegrino, J. A simple device for quantitative stool thick smear technique in schistosomiasis mansoni. Revista do Instituto de Medicina Tropical de São Paulo (1972). , 14, 397-400.

[27] Abdel-wahab, M. F, Esmat, G, Farrag, A, Boraey, Y. A, \& Strickland, G. T. Grading of hepatic schistosomiasis by the use of ultrasonography. The American Journal of Tropical Medicine and Hygiene (1992). , 46, 403-408.

[28] Homeida, M, Abdel-gadir, A. F, Cheever, A. W, \& Bennett, J. L. Arbah BMO, Ibrahim SZ, Abdel-Salam IM, Dafalla AA, Nash T. Diagnosis of pathologically confirmed Symmers' periportal fibrosis by ultrasonography: A prospective blinded study. The American Journal of Tropical Medicine and Hygiene (1988). , 38, 86-91.

[29] Cerri, G. G, Alves, V. A, \& Magalhães, A. Hepatosplenic schistosomiasis mansoni: ultrasound manifestations. Radiology (1984). , 153, 777-780.

[30] Barbosa, C. S. Domingues ALC, Abath F, Montenegro SML, Guida U, Carneiro J, Tobosa B, Moraes CNL, Spinelli. Epidemiologia da esquistossomose aguda na praia de Porto de Galinhas, Pernambuco, Brasil. Caderno de Saúde Pública (2001b). , 17, 725-8.

[31] Barbosa, C. S, \& Barbosa, F. S. Padrão epidemiológico da esquistossomose em comunidade de pequenos produtores rurais de Pernambuco. Caderno de Saúde Pública (1998). , 14, 129-137.

[32] Suassuna, A, \& Coura, J. R. Esquistossomose mansoni no Estado da Guanabara: Aspectos epidemiológicos relacionados as migrações internas. Revista da Sociedade Brasileira de Medicina Tropical (1969). , 2, 59-71.

[33] Sturrock, R. F. Schistosomiasis epidemiology and control: how did we get here and where should we go? Memórias do Instituto Oswaldo Cruz (2001). , 96, 17-27.

[34] Ferreira, L. F, Naveira, J. B, \& Silva, J. R. Fase toxêmica da esquistossomose mansoni. Revista do Instituto de Medicina Tropical de São Paulo (1960). , 2, 112-120.

[35] Ferreira, H, Oliveira, C. A, Bittencourt, D, \& Katz, N. Carneiro LFC, Grinbaum E, Veloso C, Dias RP, Alvarenga RJ, Dias CB. A fase aguda da esquistossomose mansoni. Jornal Brasileiro de Medicina (1966). , 11, 54-67.

[36] Massara, C. L, Amaral, G. L, Caldeira, R. L, Drummond, S. C, Enk, M. J, \& Carvalho, O. S. Schistosomiasis in an ecotourism area in Minas Gerais State, Brazil. Caderno de Saúde Pública (2008). , 24(7), 1709-1712. 
[37] Lunde, M. N, \& Ottesen, E. A. Enzyme-linked immunosorbent assay (ELISA) for detecting $\operatorname{IgM}$ and $\operatorname{IgE}$ antibodies in human schistosomiasis. The American Journal of Tropical Medicine and Hygiene (1980). , 29, 82-85.

[38] Evengard, B, \& Hammarstrom, L. Smith CIE, Linder E. Early antibody responses in human schistosomiasis. Clinical \& Experimental Immunology (1990). , 80, $69-76$.

[39] Pessoa, S. B, \& Amorin, J. P. Notas sobre a epidemiologia da esquistossomose mansônica em algumas localidades de Alagoas. Revista Brasileira de Medicina (1957). , $14,420-422$.

[40] Kloetzel, K. Schistosomiasis in Brazil: does social development suffice? Parasitology Today (1989). , 5, 386-391.

[41] Lambertucci, J. R. Acute schistosomiasis: Clinical, diagnostic and therapeutic features. Revista do Instituto de Medicina Tropical de São Paulo (1993). , 35, 399-404.

[42] Garcia-palmieri, M. R, \& Marcial-rojas, R. A. The protein manifestations of schistosomiasis mansoni. Annals of Internal Medicine (1962). , 57, 763-775.

[43] Rocha MOCPedroso ERP, Greco DB, Lambertucci JR, Katz N, Rocha RL, Rocha RS, Rezende DF, Neves J. Pathogenetic factors of acute schistosomiasis mansoni: correlation of worm burden, IgE, blood eosinophilia and intensity of clinical manifestations. Tropical Medicine \& International Health (1996). , 2, 213-220.

[44] Diaz-rivera, R. S, Ramos-morales, F, \& Koppisch, E. Acute Manson's schistosomiasis. The American Journal of Medicine (1956). , 21, 918-943.

[45] Greco, D. B, Pedroso, E. R, Lambertucci, J. R, Rocha, M. O, Coelho, P. M, Raso, P, \& Ferreira, C. S. Pulmonary involvement in schistosomiasis mansoni. Memórias do lnstituto Oswaldo Cruz (1987). , 82, 221-227.

[46] Neves, J. Esquistossomose Mansoni: Clínica da Forma Aguda ou Toxêmica. Rio de Janeiro: Medsi Médico e Clínica Ltda (1986).

[47] Rocha MOCPedroso ERP, Neves J, Rocha RS, Greco DB, Lambertucci JR, Rocha RL, Katz N. Characterization of the non-apparent clinical form in the initial phase of schistosomiasis mansoni. Revista do Instituto de Medicina Tropical de São Paulo (1993). , 35, 247-251.

[48] Babapulle, F. B. The eosinophilias, including the idiopathic hypereosinophilic syndrome. British Journal of Haematology (2003). , 121, 203-223.

[49] Rumbley, C. A, Sugaya, H, Zekavat, S. A, El Refaei, M, Perrin, P. J, \& Phillips, S. M. Activated eosinophils are the major source of Th2-associated cytokines in the schistosome granuloma. Journal Immunology (1999). , 162, 1003-1009.

[50] De Andres, B, Rakasz, E, Hagen, M, Mccormik, M. L, Mueller, A. L, Elliot, D, Metwali, A, Sandor, M, Britigan, B. E, Weinstock, J. V, \& Lynch, R. G. Lack of Fc-epsilon re- 
ceptors on murine eosinophils: implications for the functional significance of elevated IgE and eosinophils in parasitic infections. Blood (1997). , 89, 3826-36.

[51] Cara, D. C, Negrao-correa, D, \& Teixeira, M. M. Mechanisms underlying eosinophil trafficking and their relevance in vivo. Histology and Histopathology (2000). , 15, 899-920.

[52] Gleich, G. J, Loegering, D. A, \& Maldonado, J. E. Identification of a major basic protein in guinea pig eosinophil granules. The Journal of Experimental Medicine (1973). , 137, 1459-1461.

[53] Weller, P. F. The immunology of eosinophils. The New England Journal of Medicine (1991). , 324, 1110-1118.

[54] Gleich, G. J, Frigas, E, Loegering, D. A, Wassom, D. L, \& Steinmuller, D. Cytotoxic properties of the eosinophil major basic protein. Journal of Immunology (1979). , 123, 2925-2927.

[55] Butterworth, A. E, Wassom, D. L, Gleich, G. J, Loegering, D. A, \& David, J. R. Damage to schistosomula of Schistosoma mansoni induced by eosinophil major basic protein. Journal of Immunology (1979). , 122, 221-229.

[56] Jong, E. C. Mahmoud AAF, Klebanoff SJ. Peroxidase-mediated toxicity to schistosomula of Schistosoma mansoni. Journal of lmmunology (1981). , 126, 468-477.

[57] Ackerman, S. J, Gleich, G. J, Loegering, D. A, Richardson, B. A, \& Butterworth, A. E. Comparative toxicity of purified human eosinophil granule cationic proteins for schistosomula of Schistosoma mansoni. The American Journal of Tropical Medicine and Hygiene (1985). , 34, 735-745.

[58] Gleich, G. J, Schroeter, A. L, Marcoux, J. P, Sachs, M. I, Connell, O, \& Kohler, E. J. PF. Episodic angiodema associated with eosinophilia. The New England Journal of Medicine (1984). , 310, 1621-1626.

[59] De Souza, J. R. Morais CNL, Aroucha ML, Miranda PJC, Barbosa CS, Domingues ALC, Junior LBC, Abath FGC, Montenegro SML. Treatment of human acute schistosomiasis with oxamniquine induces an increase in interferon- $\gamma$ response to Schistosoma mansoni antigens. Memórias do Instituto Oswaldo Cruz (2007). , 102(2), 225-228.

[60] Pereira, W. R, Kloos, H, Crawford, S. B, Velásquez-melendez, J. G, Matoso, L. F, Fujiwara, R. T, Cançado, G. G, Loverde, P. T, Correa-oliveira, R, \& Gazzinelli, A. Schistosoma mansoni infection in a rural area of the Jequitinhonha Valley, Minas Gerais, Brazil: analysis of exposure risk. Acta Tropica (2010). , 113(1), 34-41.

[61] Oliveira, D. M, Gustavson, S, Silva-teixeira, D. N, \& Goes, A. M. Nitric Oxide and IL-10 Production Induced by PIII- A Fraction of Schistosoma mansoni Adult Worm Antigenic Preparation-Associated with Downregulation of In Vitro Granuloma Formation. Human Immunology (1999). , 60, 305-311. 
[62] Brunet, L. R. Nitric oxide in parasitic infections. International Immunopharmacology (2001). , 1, 1457-1467.

[63] Colasanti, M, Gradoni, L, Mattu, M, Persichini, T, Salvati, L, Venturini, G, \& Ascenzi, P. Molecular basis for the anti-parasitic effect on NO. International Journal of Molecular Medicine (2002). , 9, 131-134.

[64] Rai, G, Sayed, A. A, Lea, W. A, Luecke, H. F, Chakrapani, H, Prast-nielsen, S, Jadhav, A, Leister, W, Shen, M, Inglese, J, Austin, C. P, Keefer, L, Arnér, E. S, Simeonov, A, Maloney, D. J, Williams, D. L, \& Thomas, C. J. Structure mechanism insights and the role of nitric oxide donation guide the development of oxadiazole-2-oxides as therapeutic agents against schistosomiasis. Journal of Medicinal Chemistry (2009). , 52, 6474-83.

[65] James, S. L, \& Glaven, J. Macrophage cytotoxicity against schistosomula of Schistosoma mansoni involves arginine-dependent production of reactive nitrogen intermediates. Journal of Immunology (1989). , 143, 4208-4212.

[66] Brunet, L. R, Beall, M, Dunne, D. W, \& Pearce, E. J. Nitric oxide and the th2 response combine to prevent severe hepatic damage during Schistosoma mansoni infection. Journal of Immunology (1999). , 163, 4976-4977.

[67] Abath FGCMorais CNL, Montenegro CEL, Wynn TA, Montenegro SML. Immunopathogrnic mechanisms in schistosomiasis: what can be learnt from human studies? Trends in Parasitology (2006). , 2, 85-91.

[68] Ramos, R. P, Costa, V. M, Melo, C. F, Souza, V. M, Malagueño, E, Coutinho, E. M, Abath, F. G, \& Montenegro, S. M. Preliminary results on interleukin-4 and interleukin-10 cytokine production in malnourished, inducible nitric oxide synthase-deficient mice with schistosomiasis mansoni infection. Memórias do Instituto Oswaldo Cruz (2006). , 101(1), 331-332.

[69] Forsberg, L, Floren, C. M, Mederstrom, E, \& Prytz, H. Ultrasound examination in diffuse liver disease: clinical significance of enlarged lymph nodes in the hepato-duodenal ligament. Acta Radiologica (1987). , 28, 281-284.

[70] Giorgio, A, Amoroso, P, Lettien, G, Firelli, L, De Stefano, G, Pesce, G, Scala, V, \& Pierri, P. Ultrasound evaluation of uncomplicated and complicated acute viral hepatitis. Journal of Clinical Ultrasound (1986). , 14, 675-679.

[71] Marchal, G, Oyen, R, Verschakelen, J, Gelin, J, Baert, A. L, \& Stessens, R. C. Sonographic appearence of normal lymph nodes. American Institute of Ultrasound in Medicine (1985). , 4, 417-419.

[72] Vassallo, P, Wernecke, K, Roos, N, \& Peters, P. E. Differentiation of benign from malignant superficial lymphadenopathy: the role of high-resolution US. Radiology (1992). , 183, 215-220. 
[73] Yee, J. M, Raghavendra, B. N, Horii, S. C, \& Ambrosino, M. Abdominal sonography in AIDS. A review. American Institute of Ultrasound in Medicine (1993). , 12, 705-714.

[74] Kardorff, R, Gabone, R. M, Mugashe, C, Obiga, D, Ramarokoto, C. E, Mahlert, C, Spannbrucker, N, Lang, A, Günzler, V, \& Gryseels, B. Ehrich JHH, Doehring E. Schistosoma mansoni-related morbidity on Ukerewe Island, Tanzania: clinical, ultrasonographical and biochemical parameters. Tropical Medicine \& International Health (1997). , 2, 230-239.

[75] Aquino RTRChieffi PP, Catunda SM, Araújo MF, Ribeiro MCSA, Taddeo EF, Rolim EG. Hepatitis B and C virus markers among patients with hepatosplenic mansonic schistosomiasis. Revista do Instituto de Medicina Tropical de São Paulo (2000). , 42, 313-320.

[76] Alves-júnior, A, Fontes, D. A, \& Melo, V. A. Machado MCC, Cruz JF, Santos EAS. Hipertensão portal esquistossomótica: influência do fluxo sanguíneo portal nos níveis séricos das enzimas hepáticas. Arquivos de Gastroenterologia (2003). , 40, 203-208.

[77] Martins, R. D, \& Borges, D. R. Ethanol challenge in non-alcoholic patients with schistosomiasis. Journal of Clinical Pathology (1993). , 46, 250-253. 
(C) 2013 The Author(s). Licensee IntechOpen. This is an open access article distributed under the terms of the Creative Commons Attribution 3.0 License, which permits unrestricted use, distribution, and reproduction in any medium, provided the original work is properly cited. 